Article

\title{
Practical Maximum-Power Extraction in Single Microbial Fuel Cell by Effective Delivery through Power Management System
}

\author{
Jeongjin Yeo ${ }^{1}$, Taeyoung Kim ${ }^{2}{ }^{\mathbb{D}}$, Jae Kyung Jang ${ }^{2}$ and Yoonseok Yang ${ }^{1, *}$ \\ 1 Division of Biomedical Engineering, Chonbuk National University, 567 Baekje-daero, Deokjin-gu, Jeonju-si, \\ Jeollabuk-do 54896, Korea; yeojjin85@gmail.com \\ 2 Energy and Environmental Engineering Division, National Institute of Agricultural Sciences, \\ Rural Development Administration, 310 Nongsaengmyeong-ro, Wansan-gu, Jeonju-si, Jeollabuk-do 54875, \\ Korea; duftlaglkty@gmail.com (T.K.); jkjang1052@korea.kr (J.K.J.) \\ * Correspondence: ysyang@jbnu.ac.kr; Tel.: +82-(63)-270-4068
}

Received: 2 August 2018; Accepted: 1 September 2018; Published: 2 September 2018

check for updates

\begin{abstract}
Power management systems (PMSs) are essential for the practical use of microbial fuel cell (MFC) technology, as they replace the unstable stacking of MFCs with step-up voltage conversion. Maximum-power extraction technology could improve the power output of MFCs; however, owing to the power consumption of the PMS operation, the maximum-power extraction point cannot deliver maximum power to the application load. This study proposes a practical power extraction for single MFCs, which reserves more electrical energy for an application load than conventional maximum power-point tracking (MPPT). When experimentally validated on a real MFC, the proposed method delivered higher output power during a longer PMS operation time than MPPT. The maximum power delivery enables more effective power conditioning of various micro-energy harvesting systems.
\end{abstract}

Keywords: microbial fuel cell; energy harvesting; power management system; maximum-power point; constant voltage ratio maximum power-point tracking (MPPT)

\section{Introduction}

A microbial fuel cell (MFC) system is usually developed by stacking many small-sized unit cells in series or parallel configurations until the MFC meets the output power requirements. Such miniaturized implementation of electrochemical cells improves the bioelectric interactions, electron transfer and mass transport of the organic substrate, delivering higher power output than single bulk implementations [1,2].

The maximum attainable MFC voltage is theoretically on the order of $1.1 \mathrm{~V}$ and an MFC delivers an output voltage below 1 volt when connected to a load resistance (closed-circuit voltage) [3]. For practical use, the MFC voltage should be upconverted to the level compliant with most electric facilities.

A series stack of single MFC's is a simple and conventional way of converting the low-level output voltage to a higher level, but the voltages of individual cells cannot be controlled precisely or maintained constantly. Therefore, exactly matching the output voltage to the required value is a difficult task [4-8].

More importantly, as the bioelectrochemical characteristics of cells in a series configuration cannot remain uniform or consistent over time, cells with uneven current strength can interact to cause the so-called voltage reversal phenomenon [9]. Cells with reversed voltage not only cease contributing to the total output, but also degrade the total output of the series stack by creating a huge 
internal resistance in the series circuit. In the worst-case scenario, the voltage reversal damages the cell itself, requiring costly (in terms of time and effort) restoration of its bioelectric interface [10-12]. Though many researches have investigated this phenomenon, the exact cause and an appropriate solution remain unreported.

To maintain precise and consistent control of the output voltage, one can apply step-up conversion by a power management system (PMS) composed of integrated circuits (IC's). A PMS regulates the MFC output, guaranteeing that the MFC power is compatible with the many electric devices in the MFC application. The complications of adding circuit components does not negate the extended usability ensured by the output regulation. Moreover, the series-stacked MFCs, each of which is installed with the PMS, prevent the unbalanced current from damaging the bioelectric interface in the cells by confining the reversed voltage to the energy-storage components at the end of the PMS, where it cannot affect the bioelectrochemical cell. Consequently, the current flows through the series stack circuit and only the individual voltages of the properly working cells are summed. The PMS also regulates the varying outputs of individual cells, which differ in their bioelectrochemical characteristics even when made of identical components, because they are inoculated with different organic wastes. Therefore, PMSs are essential for the industrialization of MFC technology [13,14].

By better understanding the interaction between MFCs and electric circuits, we could maximize the electric power extracted from the MFCs. In many attempts to improve the electricity generation of MFC, the performance assessment of the cells assumes a static resistive load [1-12]. However, in real applications, the output electricity must be converted to a higher voltage or current level for compatibility with the practical load. Moreover, the power extracted from an MFC varies with the load impedance. Maximum power point tracking (MPPT) controls the current flow into the PMS, allowing the PMS to maximize the power extraction from the MFCs [14-17]. MPPT significantly increases the power obtained from natural energy resources such as solar and wind energy, while consuming negligible power through the current-sweep operation of its microcontroller unit (MCU) [18-21]. However, MPPT in MFC applications remains in the experimental stage, because the power produced by the unit cell is very small. Therefore, the power consumption of the MCU for MPPT operation is comparable to the MFC output, significantly decreasing the power delivered to the load application. Conventional MPPT can extract maximum power from an MFC energy source but cannot deliver maximum power to the application load. To maintain high power delivery to the application, the power consumption of the MPPT and PMS must be heavily reduced [14].

Furthermore, the power consumption of an IC, over its entire operation range, cannot be minimized universally because it depends on the operating voltage and current conditions even if the use of MCU is avoided. Therefore, it is important to investigate the effect of self-power consumption on its performance under different operating conditions.

This study proposed an effective power extraction for single MFCs that reserves more electric energy for the application load than conventional MPPT. The proposed method was tested in an MFC experimental setup, and its feasibility and practicability was confirmed by its improved performance.

\section{Materials and Methods}

\subsection{Microbial Fuel Cell (MFC) Setup}

Figure 1 is a schematic of an MFC and its batch-mode prototype, in which microbes generate electrons from organic substances. The total volume $\left(14 \times 14 \times 11=2156 \mathrm{~cm}^{3}\right)$ comprises an anodic and a cathodic chamber, each of volume $11 \times 11 \times 4=484 \mathrm{~cm}^{3}$. The cathode is a carbon cloth (W0S1002, CeTech, Taiwan), and the cathode is a carbon cloth containing $0.5 \mathrm{mg} / \mathrm{cm}^{2}(20 \%)$ platinum (EC2019, Fuel Cell Earth, Woburn, MA, USA). The area coverage of both cathode and anode is $11 \times 11=121 \mathrm{~cm}^{2}$. 


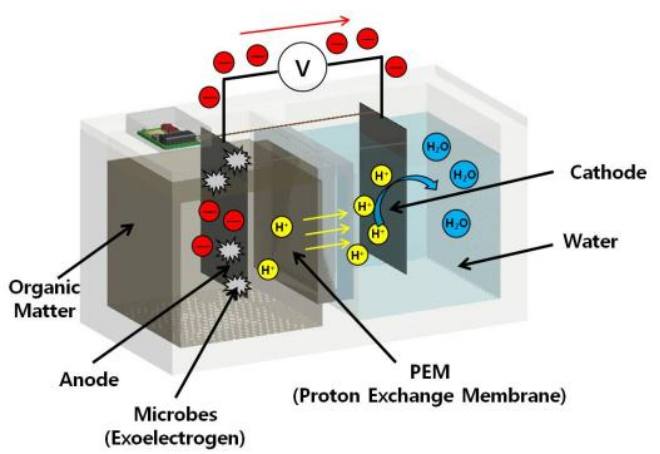

(a)

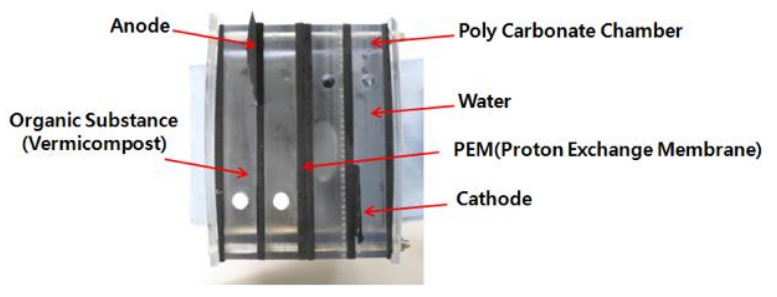

(b)

Figure 1. Batch-mode microbial fuel cell (MFC): (a) Working principle; (b) Developed prototype.

The MFC anolyte is worm juice obtained from vermicompost earthworms fed with vegetables, fruit peels and coffee waste. The digestive tract of earthworms contains a rich community of exo-electrogenic microbial species, including Geobacter sulfurreducens, as well as abundant organic substances [22]. Earthworm juice is proven to be a convenient MFC anolyte [23] because it requires no concentration of the culture or additional inoculation of exo-electrogenic species.

At the beginning of batch-mode operation, the anodic and cathodic chambers of the MFC were filled with $400 \mathrm{~mL}$ of anolyte and $400 \mathrm{~mL}$ of water, respectively. The chambers are separated by a proton exchange membrane (Nafion NR-212, Dupont, Wilmington, DE, USA) with an area of $11 \times 11=121 \mathrm{~cm}^{2}$.

\subsection{Output Characteristics of the Prototyped MFC}

To elucidate the current-voltage (I-V) characteristics of the developed MFC and the parameters related to maximum power extraction, the polarization curve was obtained in preliminary experiments under varying resistive loads (see Figure 2).

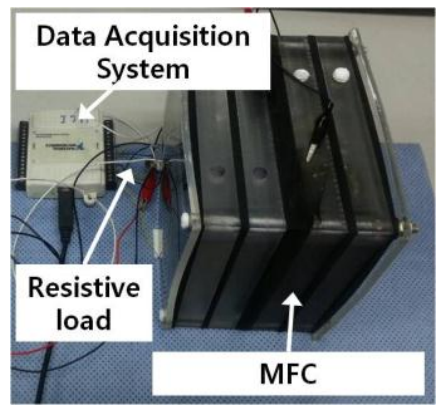

(a)

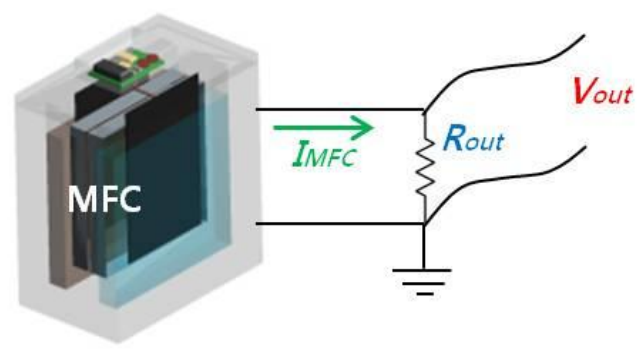

(b)

Figure 2. Experimental setup for characterizing the electricity generated by the MFC: (a) Measurement setup; (b) Schematic of circuit with varying resistive load.

The open circuit voltage $V_{o c}$ was maximized at $0.85 \mathrm{~V}$ and delivered a maximum power of $0.512 \mathrm{~mW}$ when connected to the resistive load of an application as shown in Figure 3, which drew $1.6 \mathrm{~mA}$ at $0.32 \mathrm{~V}$ (corresponding to approximately $40 \% V_{o c}$ ). Therefore, the power output can be maximized by controlling the load impedance to maintain the output voltage at $40 \%$ of the $V_{o c}$. 


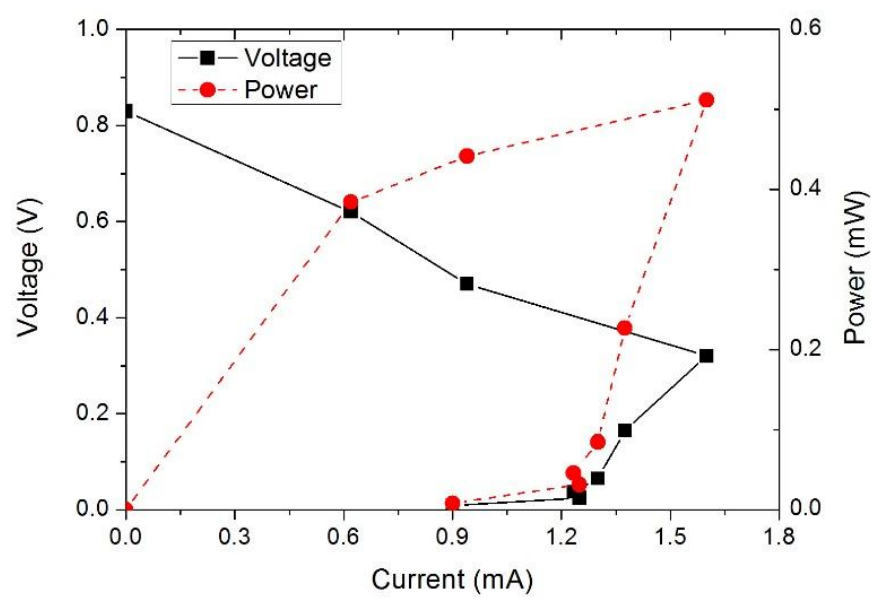

Figure 3. Output characteristics of the MFC.

\subsection{Power Management System (PMS) with Constant Voltage Ratio Maximum Power Point Tracking (MPPT)}

A constant voltage ratio MPPT uses the pre-acquired maximum power condition of the input energy source (i.e., $40 \% V_{o c}$ ) as a reference voltage. When the MFC voltage is adjusted to the reference voltage, maximum power can be drawn from the source. Compared with the conventional current-sweep MPPT, which tracks the maximum power point by measuring and calculating the sourced power in real-time, the maximum extracted power by the proposed MTTP can deviate slightly from the true maximum, but it greatly simplifies the maximum power extraction and requires no extra power source to support its tiny power consumption. It was implemented using a commercial integrated circuit (IC) (BQ25504, Texas Instruments, Dallas, TX, USA) as shown in Figure 4a. The operation begins at input voltages as low as $330-450 \mathrm{mV}$ and converts the MFC output voltages from below 1.0 V to levels compatible with electric devices ( $3.8 \mathrm{~V})$. As shown in Figure $4 \mathrm{~b}$, the MPPT reference voltage can be configured by inserting external resistors into the circuit. The external resistors $R_{o c 1}$ and $R_{o c 2}$ are designed to establish the voltage ratio in Equation (1), where $V_{r e f}$ is the reference voltage [24].

$$
V_{r e f}=V_{o c}\left(\frac{R_{o c 1}}{R_{o c 1}+R_{o c 2}}\right)
$$

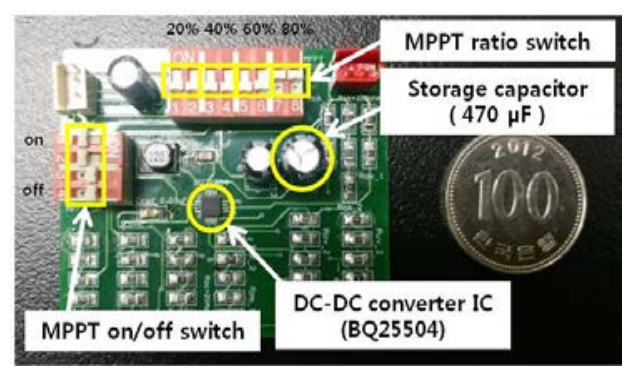

(a)



(b)

Figure 4. Power management system (PMS) operated under constant voltage ratio maximum power point tracking (MPPT): (a) Printed circuit board (PCB) implementation; (b) Schematic of the developed PMS with MPPT control.

Based on this voltage ratio, the constant voltage ratio MPPT extracts power from the MFC while adjusting its input impedance by Pulse Frequency Modulation (PFM). To evaluate the performance 
under different operating conditions, the voltage ratio was varied around the optimal $40 \%(20 \%$, $60 \%$ and $80 \%$ ).

\section{Results and Discussion}

\subsection{Performance Characteristics of the PMS under Different Operating Conditions}

The power-extraction performance, self-power consumption, and power delivery to an application load of the developed PMS was tested at different voltage ratios, as shown in Figure 5. To ensure consistent results through controlled experiments, the input energy to the PMS was independently provided by a precision source meter (B2902A, Keysight Technologies, Santa Rosa, CA, USA). The meter supplied 800-mV voltage to the PMS input, simulating the small output voltage of the MFC obtained in preliminary experiments. The current input (which also simulates the MFC output characteristics) was reduced by adding a small resistance $\left(R_{i n}\right)$ between the MFC output and the PMS input. The input power to the PMS was calculated in real-time by measuring the voltage across $R_{i n}$. The final output power delivered to the application load was determined by similar measurements of the voltage across $R_{\text {out }}$. All voltages were measured by a data acquisition system, DAQ6009 (National Instruments, Austin, TX, USA) and LabVIEW2009 (National Instruments, USA) at a sampling frequency of $1000 \mathrm{~Hz}$.

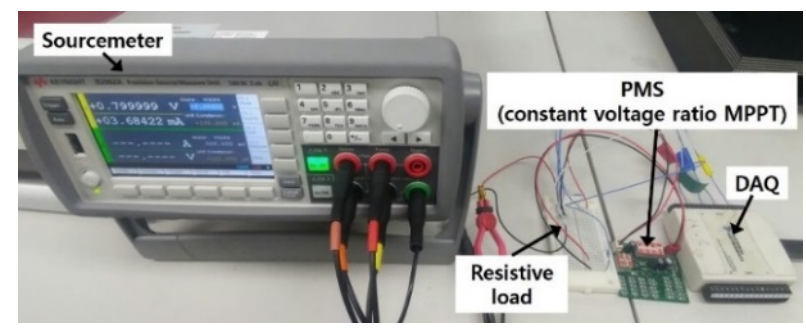

(a)

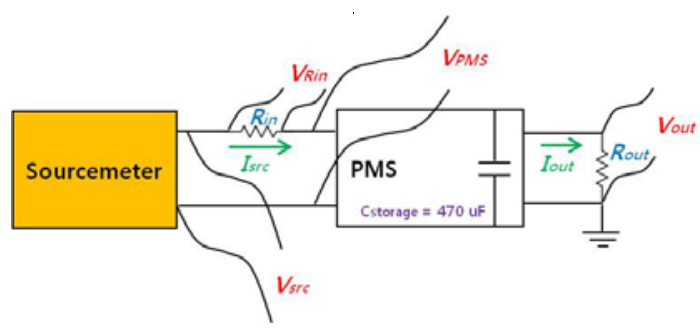

(b)

Figure 5. Experiments for evaluating the performance characteristics of PMS with different voltage ratios: (a) Experimental setup using the precision source meter as an energy source; (b) Circuit schematic showing the measured voltages.

Figure 6 shows the power output of the source meter (which is input to the PMS) and the output power from the PMS operated at different reference voltage ratios $\left(20 \%, 40 \%, 60 \%\right.$, and $\left.80 \% V_{\text {oc }}\right)$. As the voltage ratio increased, the power of the source meter exhibited the typical characteristic of an ideal voltage source with internal resistance, being maximized between $40 \%$ and $60 \% V_{o c}$. However, the output power of the PMS, which is conditioned by the PMS and delivered to the application load, exhibited different behavior. In particular, the PMS delivered a large output power when operated at $80 \% V_{o c}\left(0.649 \mathrm{~mW}\right.$, comparable to that of $\left.20 \% V_{o c}, 0.654 \mathrm{~mW}\right)$ despite its small input from the source meter. This result can be explained by the efficiency dependence of PMS on the voltage ratio (see Figure 6b). The impedance-adjusting circuit in the PMS consumes more electric power when drawing more current with faster PFM switching. The PMS has its own power consumption profile, which is significant, especially when drawing from low power sources such as MFCs. Therefore, the maximum power extraction does not guarantee maximum power delivery to the application load through the PMS. 


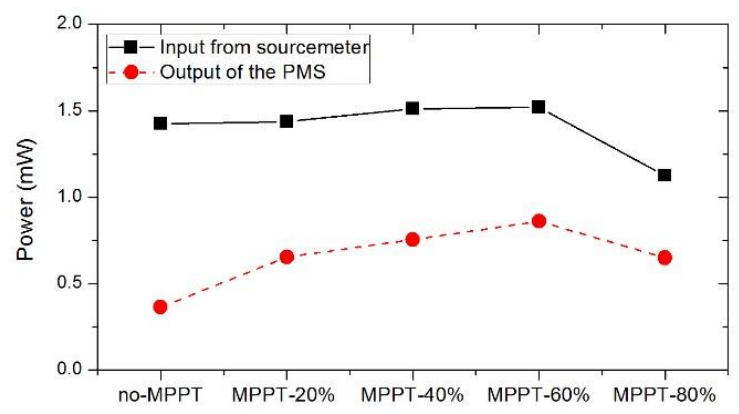

(a)

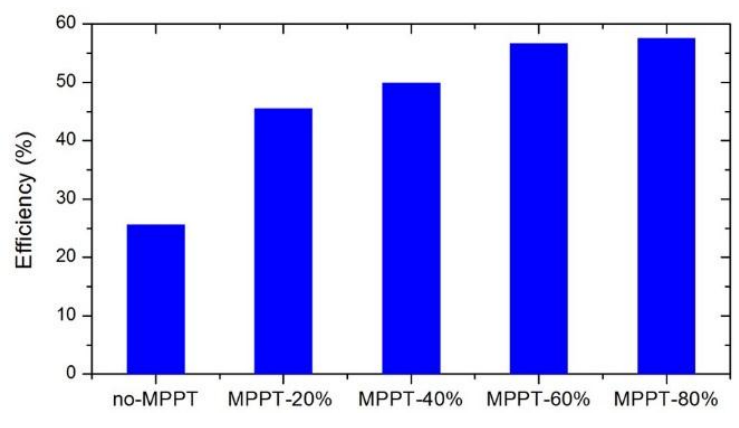

(b)

Figure 6. Performance characteristics of developed PMS: (a) Input power from the source meter and output power of the PMS as functions of voltage ratio; (b) Conversion efficiencies of the PMS in different voltage-ratio configurations.

\subsection{Power Extraction from the MFC Using the PMS}

To examine the MPPT and voltage conversion performance of the PMS, the developed PMS was applied to the MFC prototype. The experimental set up and procedures (see Figure 7) were similar to those in Section 3.1, except that the source characteristic of the real MFC differed from ideal voltage source. A tiny resistance $\left(R_{i n}=2 \Omega\right)$ was inserted in the input current pathway for measuring purposes only, and a resistive load $\left(R_{\text {out }}=5000 \Omega\right)$ was connected to the PMS output. In the experimental verification, the current requirement of $R_{\text {out }}$ was set higher than that of the power delivery from the MFC and PMS, mimicking a real application load. All voltages were measured and recorded by the DAQ6009 and LabVIEW2009 instruments (National Instruments, Austin, TX, USA) sampling at $1000 \mathrm{~Hz}$.

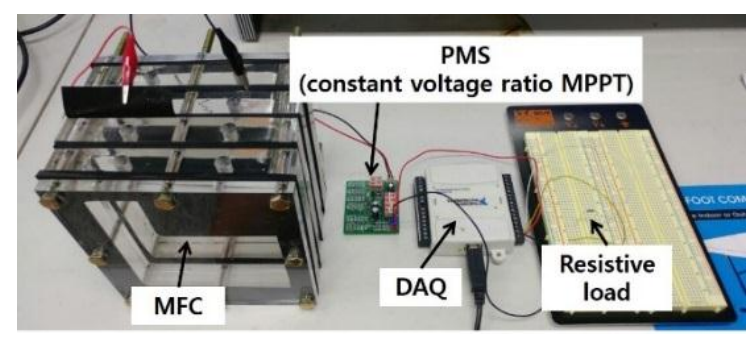

(a)

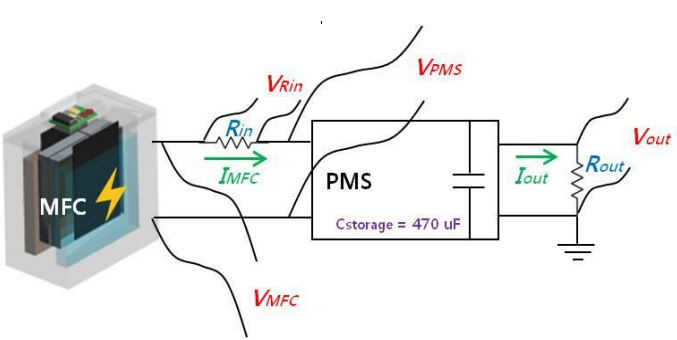

(b)

Figure 7. Experiments for examining the PMS performance on an MFC with different voltage ratios: (a) Experimental setup using the MFC prototype as an energy source; (b) Circuit schematic showing the measured voltages.

Figure 8 shows the measured voltages of the PMS input and output in five experimental configurations. The corresponding powers calculated in each configuration are shown in Figure 9. The MFC voltage $\left(V_{o c}\right)$ was approximately $0.85 \mathrm{~V}$ at the beginning, and changed at the start of the MPPT operation. The PMS was designed to convert the input voltage up to $3.8 \mathrm{~V}$ for typical application loads, but the MFC provided insufficient input power to maintain such voltages across $R_{\text {out }}$. Consequently, the output voltage gradually decreased over time. At input voltages below $0.36 \mathrm{~V}$, the PMS ceased operation. The total duration of the PMS operation depended on the voltage ratio of the MPPT, because the available power differed in each configuration. 


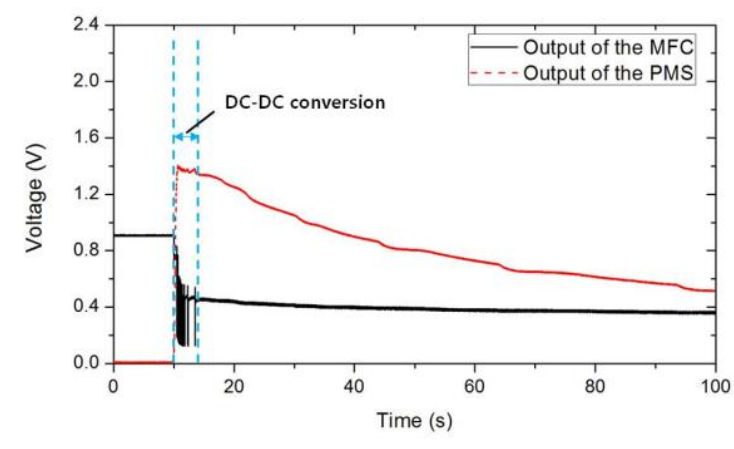

(a)

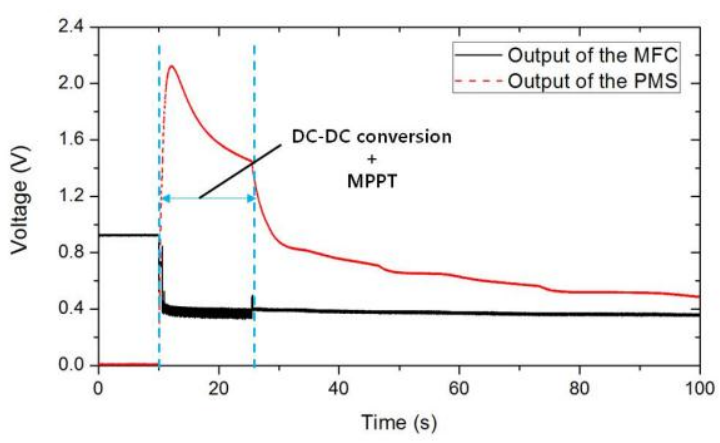

(c)



(b)

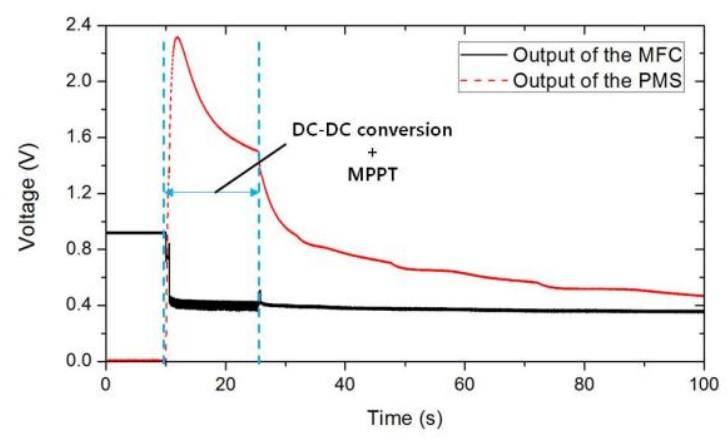

(d)

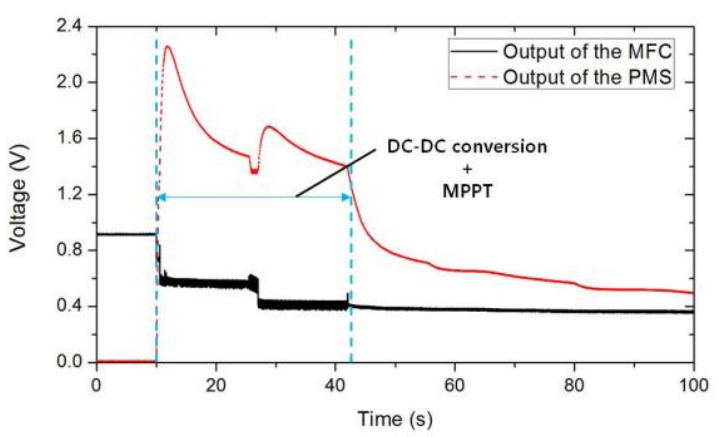

(e)

Figure 8. Output voltage of the MFC and PMS at different voltage ratios: (a) no MPPT; (b) MPPT-20\%; (c) MPPT-40\%; (d) MPPT-60\%; (e) MPPT-80\%.

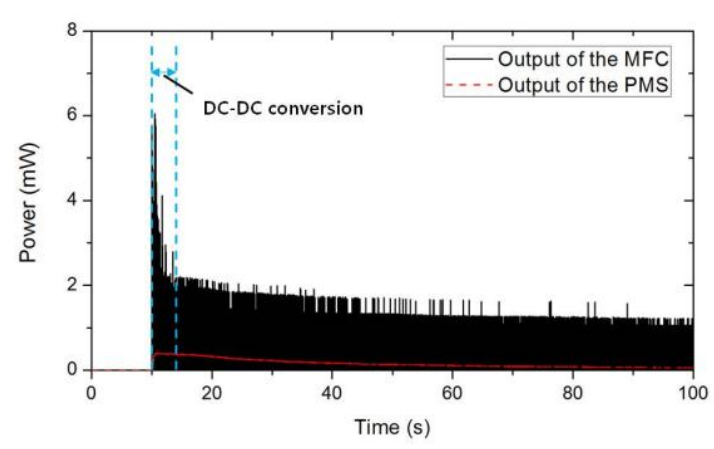

(a)

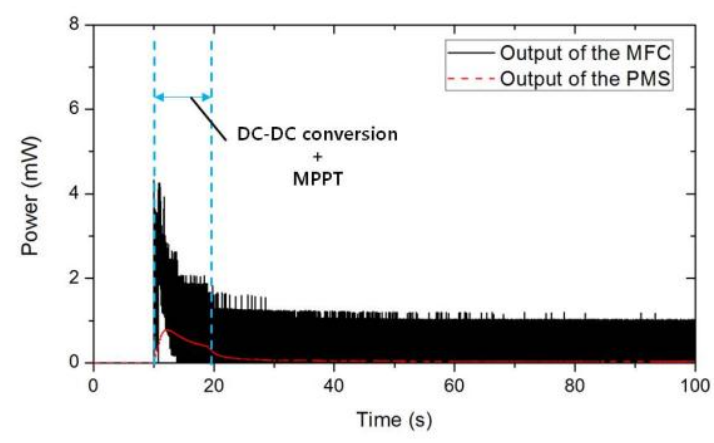

(b)

Figure 9. Cont. 


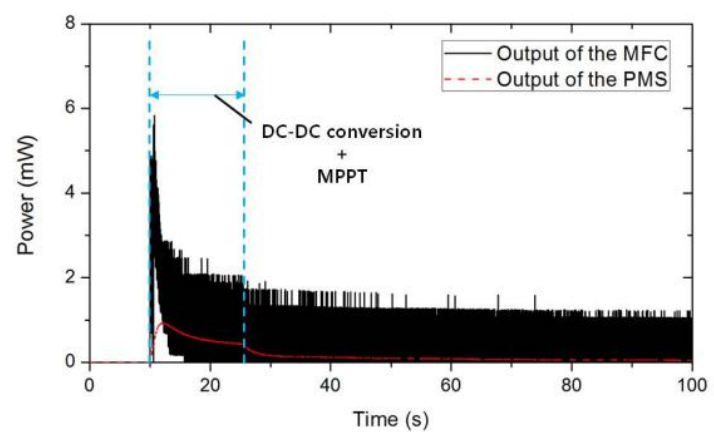

(c)

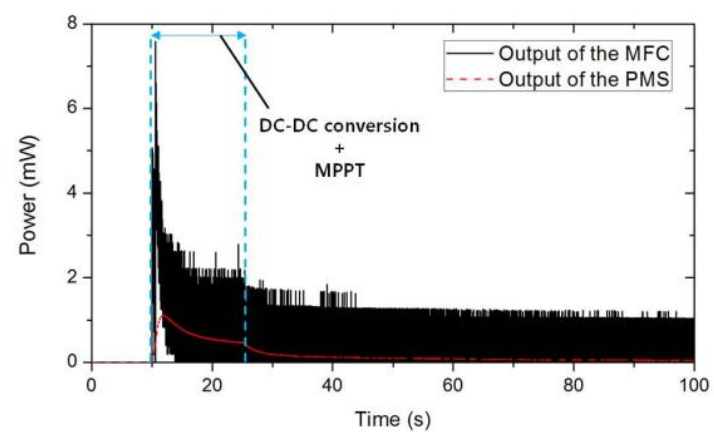

(d)

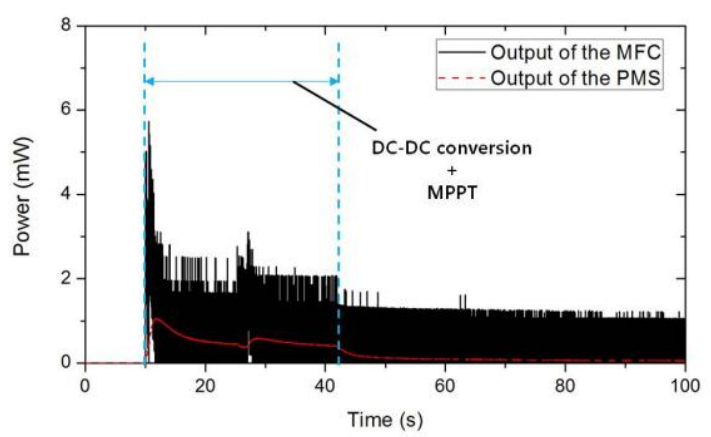

(e)

Figure 9. Output powers of the MFC and PMS at different voltage ratios: (a) no MPPT; (b) MPPT-20\%; (c) MPPT-40\%; (d) MPPT-60\%; (e) MPPT-80\%.

Figures 8a and 9a show the performance of the PMS operation without MPPT. The average input power was $1.6 \mathrm{~mW}$ and the input voltage was successfully converted for only $3.5 \mathrm{~s}$. The performance may have been degraded by the high current extraction out of the MFC by the PMS without MPPT. Consequently, the PMS operation was short-lived and only $0.36 \mathrm{~mW}$ of power (on average) was delivered to the resistive load Rout. Under the 20\% voltage-ratio MPPT, the PMS extracted an average power of $1.22 \mathrm{~mW}$ from the MFC for $9 \mathrm{~s}$, enabling successful voltage conversion (Figure $8 \mathrm{~b}$ ). The average power delivered to the load was $0.55 \mathrm{~mW}$ (Figure $9 \mathrm{~b}$ ). Under the $40 \%$ voltage-ratio MPPT, the average power extracted from the MFC was $1.24 \mathrm{~mW}$ for $25 \mathrm{~s}$ (Figure 8c), enabling voltage conversion by the PMS and delivering an average power of $0.60 \mathrm{~mW}$ to the load (Figure 9c). Under the $60 \%$ voltage-ratio MPPT, the PMS operated for $26 \mathrm{~s}$, extracting an average power of $1.1 \mathrm{~mW}$ (Figure $8 \mathrm{~d}$ ) and delivering an average up-converted power of $0.65 \mathrm{~mW}$ to the load (Figure $9 \mathrm{~d}$ ). Under the $80 \%$ voltage-ratio MPPT, the power performance declined with $0.63 \mathrm{~mW}$ average power extracted from the MFC in $42 \mathrm{~s}$ (Figure 8e), and $0.54 \mathrm{~mW}$ average power delivered to the load (Figure 9e). However, there were two consecutive voltage conversions in Figure 8e with the operation time extended, suggesting that sufficient power was supplied from the MFC, or was more efficiently used than in the other configurations. In addition, the small current extraction maintaining a high voltage may have prevented an abrupt increase in current extraction out of the MFC, which accompanied the sudden performance degradation as in the no-MPPT configuration.

Figure 10a summarizes the average power extracted from the MFC and the average power delivered to the resistive load by PMS in different voltage-ratio configurations. Figure 10b shows the efficiencies calculated from the corresponding input and output PMS powers in Figure 10a. The MFC output was maximized at $40 \%$ voltage ratio, close to the maximum power point of the MFC shown in Figure 10a (37\%). Successful power-extraction performance was verified except for the anomalous result in the no-MPPT configuration. The unexpectedly high MFC output in the no-MPPT extraction 
is related to the corresponding efficiency trend in Figure 10b. The no-MPPT configuration did not necessarily extract more power from the MFC than any of the MPPT configurations. When initially connected to the PMS, the MFC usually provides some residual power stored in its electrodes. The no-MPPT circuits instantly drew a large current over a short duration. The operation time of the no-MPPT configuration was the shortest among the configurations, because there was insufficient energy to maintain the operation. Consequently, the calculated average input power during operation was the highest in this configuration, but the operating efficiency was the lowest. This effect becomes evident in Figure 11, which shows the corresponding converted energies.



(a)



(b)

Figure 10. (a) Average input power from the MFC and output power of the PMS as functions of MTTP voltage ratio: (b) Efficiencies of the PMS in different MTTP voltage-ratio configurations.

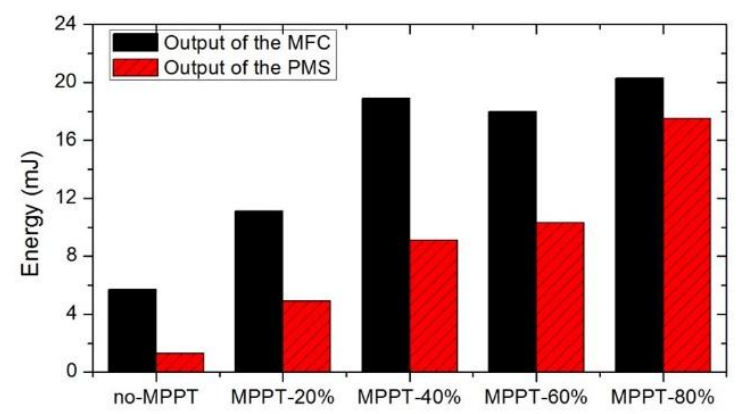

Figure 11. Energy performances in different voltage-ratio configurations.

The voltage-ratio configuration should affect not only the power extraction, but also the power finally delivered to the load resistance Rout. The maximum power was delivered not at $40 \% V_{o c}$ of the MFC voltage (which maximized the extracted power; see Figure 10 ), but at $60 \% V_{o c}$. This occurs because the self-power consumption of the PMS depends on the input voltage and current during its operation as mentioned above, which accords with the efficiency variation shown in Figure 10b. The different operation durations, which also depend on the available energy supply, might confuse the power analysis of the results. Therefore, Figure 11 displays the changing performance from an energy point of view. The largest energy $(17.5 \mathrm{~mJ})$ was delivered to the load resistance from $20.3 \mathrm{~mJ}$ of energy extracted from the MFC at an $80 \%$ voltage ratio. On the contrary, the $40 \%$ voltage ratio delivered only $9.1 \mathrm{~mJ}$ to the load resistance, although it extracted the second-largest energy from the MFC. In this analysis, the maximum energy extracted at the $80 \%$ voltage ratio resulted from the extended duration of the PMS operation, which prolonged the provision of input power to the operation. Although the limited duration causes complications in the performance assessment of the PMS operation, it is an inevitable phenomenon in MFC because the power requirement of the application load usually exceeds the output power of the MFC. Therefore, the PMS usually repeats open-close operations of the circuit connected to the MFC, accumulating sufficient energy in the buffering storage components (capacitors 
and batteries) installed between the MFC and PMS or the PMS and application load. Therefore, the prolonged availability of input power is the most effective feature in real-field applications of an MFC system since it could provide the MFC with longer intermissions for recovery between active current extracting periods, which is better for long-term performance.

\section{Conclusions}

This study proposed a practical power extraction for single MFC, which reserved more electrical energy for an application load than conventional MPPT. The feasibility and practicability of the proposed MPPT were verified in experimental tests on a real MFC. Both the operation time and output power of the PMS were higher in the proposed method than in the conventional method. Among the tested configurations, the $80 \%$ voltage-ratio configuration extracted the minimum power from the MFC, but delivered high output power due to the low power consumption of the PMS. Consequently, the PMS in the $80 \%$ voltage-ratio MPPT operated twice (versus one operation in the other conditions), extracting a large amount of energy from the MFC and transferring it to the load.

For practical applications with real MFCs, the optimal power configuration should consider not only the maximum power extraction but also the maximum PMS efficiency. The MFC power must be effectively delivered to the load application, especially when the output power of the MFC is comparable to the power consumed by the power-conditioning circuits.

The proposed method is easily incorporable into MPPT technologies employing constant-voltage ratio MPPTs, and is useful for developing new tracking algorithms in other MPPTs. Moreover, it might realize a power-conditioning system for sub-mW energy harvesting devices, which generate electric power from thermal or vibrational energy sources.

Author Contributions: J.Y. performed the experiments and analyses and drafted the paper. T.K. and J.K.J. provided theoretical analysis on the characteristics of the MFC and drafted the paper. Y.Y. supervised the experiments and analyses during the entire process and approved the final paper.

Funding: This research was funded by [Rural Development Administration] grant number [PJ011751022018].

Acknowledgments: This research was supported by the "Cooperative Research Program for Agriculture Science \& Technology Development (Project No. PJ011751022018)" of the Rural Development Administration, Korea.

Conflicts of Interest: The authors declare no conflict of interest.

\section{References}

1. Qian, F.; Morse, D.E. Miniaturizing microbial fuel cells. Trends Biotechnol. 2011, 29, 62-69. [CrossRef] [PubMed]

2. Ren, H.; Lee, H.S.; Chae, J. Miniaturizing microbial fuel cells for potential portable power sources. Microfluid. Nanofluidics 2012, 13, 353-381. [CrossRef]

3. Logan, B.E.; Hamerlers, B.; Rozendal, R.; Schröder, U.; Kelller, J.; Freguia, S.; Aelterman, P.; Verstraete, W.; Rabaey, K. Microbial Fuel Cells: Methodology and Technology. Environ. Sci. Technol. 2006, 40, 5181-5192. [CrossRef] [PubMed]

4. Aelterman, P.; Rabsey, K.; Pham, H.T.; Boon, N. Continuous electricity generation at high voltages and currents using stacked microbial fuel cells. Environ. Sci. Technol. 2006, 40, 3388-3394. [CrossRef] [PubMed]

5. Wang, B.; Han, J.I. A single chamber stackable microbial fuel cell with air cathode. Biotechnol. Lett. 2009, 31, 387-393. [CrossRef] [PubMed]

6. Kim, D.; An, J.; Kim, B.; Jang, J.K.; Kim, B.H.; Chang, I.S. Scaling-Up Microbial Fuel Cells: Configuration and Potential Drop Phenomenon at Series Connection of Unit Cells in Shared Anolyte. Chem. Sus. Chem. 2012, 5, 1086-1091. [CrossRef] [PubMed]

7. Kim, B.; An, J.; Kim, D.; Jang, J.K.; Lee, B.G.; Chang, I.S. Voltage increase of microbial fuel cells with multiple membrane electrode assemblies by in series connection. Electrochem. Commun. 2013, 28, 131-134. [CrossRef]

8. Jafary, T.; Rahimnejad, M.; Ghoreyshi, A.A.; Najafpour, G.; Hghparast, F.; Daud, W.R.W. Assessment of bioelectricity production in microbial fuel cells through series and parallel connections. Energy Convers. Manag. 2013, 75, 256-262. [CrossRef] 
9. Oh, S.E.; Logan, B.E. Voltage reversal during microbial fuel cell stack operation. J. Power Sources 2007, 167, 11-17. [CrossRef]

10. Kim, Y.; Hatzell, M.C.; Hutchinson, A.J.; Logan, B.E. Capturing power at higher voltages from arrays of microbial fuel cells without voltage reversal. Energy Environ. Sci. 2011, 4, 4662-4667. [CrossRef]

11. An, J.; Sim, J.; Lee, H.S. Control of voltage reversal in serially stacked microbial fuel cells through manipulating current significance of critical current density. J. Power Sources 2015, 283, 19-23. [CrossRef]

12. An, J.; Kim, B.; Chang, I.S.; Lee, H.S. Shift of voltage reversal in stacked microbial fuel cells. J. Power Sources 2015, 278, 534-539. [CrossRef]

13. Song, Y.E.; Boghani, H.C.; Kim, H.S.; Kim, B.G.; Lee, T.; Jeon, B.H.; Kim, J.R. Electricity Production by the Application of a Low Voltage DC-DC Boost Converter to a Continuously Operating Flat-Plate Microbial Fuel Cell. Energies 2017, 10, 596. [CrossRef]

14. Wang, H.; Park, J.D.; Ren, Z. Active energy harvesting from microbial fuel cells at the maximum power point without using resistors. Environ. Sci. Technol. 2012, 46, 5247-5252. [CrossRef] [PubMed]

15. Park, J.D.; Ren, Z. Hysteresis controller based maximum power point tracking energy harvesting system for microbial fuel cells. J. Power Sources 2012, 205, 151-156. [CrossRef]

16. Carreon-Bautista, S.; Erbay, C.; Han, A.; Sanchez-Sinencio, E. Power management system with integrated maximum power extraction algorithm for microbial fuel cells. IEEE Trans. Energy Convers. 2015, 30, $262-272$. [CrossRef]

17. Alaraj, M.; Radenkovic, M.; Park, J.D. Intelligent energy harvesting scheme for microbial fuel cells: Maximum power point tracking and voltage overshoot avoidance. J. Power Sources 2017, 342, 726-732. [CrossRef]

18. Koutroulis, E.; Kalaitzakis, K.; Voulgaris, N.C. Development of a microcontroller-based, photovoltaic maximum power point tracking control system. IEEE Trans. Power Electron. 2001, 16, 46-54. [CrossRef]

19. Verma, D.; Nema, S.; Shandilya, A.M.; Dash, S.K. Maximum power point tracking (MPPT) techniques: Recapitulation in solar photovoltaic systems. Renew. Sustain. Energy Rev. 2016, 54, 1018-1034. [CrossRef]

20. Koutroulis, E.; Kalaitzakis, K. Design of a maximum power tracking system for wind-energy system for wind-energy-conversion applications. IEEE Trans. Ind. Electron. 2006, 53, 486-494. [CrossRef]

21. Aubrée, R.; Auger, F.; Macé, M.; Loron, L. Design of an efficient small wind-energy conversion system with an adaptive sensorless MPPT strategy. Renew. Energy 2016, 83, 280-291. [CrossRef]

22. Thakuria, D.; Schmidt, O.; Finan, D.; Egan, D.; Doohan, F.M. Gut wall bacteria of earthworms: A natural selection process. ISME J. 2010, 4, 357. [CrossRef] [PubMed]

23. Youn, S.; Yeo, J.; Joung, H.; Yang, Y. Energy harvesting from food waste by inoculation of vermicomposted organic matter into Microbial Fuel Cell (MFC). In Proceedings of the 2015 IEEE SENSOS, Busan, Korea, 1-4 November 2015; pp. 1-4.

24. BQ25504 Ultra Low-Power Boost Converter with Battery Management for Energy Harvester Applications Datasheet. Available online: http:/ / www.ti.com/product/BQ25504 (accessed on 30 July 2018). 